\title{
Deep brain stimulation for Parkinson's disease: meta-analysis of results of randomized trials at varying lengths of follow-up
}

\author{
Alireza Mansouri, MD, MSc, ${ }^{1,2}$ Shervin Taslimi, MD, MPH, ${ }^{1}$ Jetan H. Badhiwala, MD, ${ }^{1}$ \\ Christopher D. Witiw, MD, ${ }^{1}$ Farshad Nassiri, MD, ${ }^{1}$ Vincent J. J. Odekerken, MD, PhD, ${ }^{3}$ \\ Rob M. A. De Bie, MD, PhD, ${ }^{3}$ Suneil K. Kalia, MD, PhD, ${ }^{1}$ Mojgan Hodaie, MD, MSc, ${ }^{1}$ \\ Renato P. Munhoz, MD, PhD, ${ }^{4}$ Alfonso Fasano, MD, ${ }^{4}$ and Andres M. Lozano, MD, PhD ${ }^{1}$
}

${ }^{1}$ Division of Neurosurgery, Toronto Western Hospital, Department of Surgery, University of Toronto; ${ }^{4}$ Morton and Gloria Shulman Movement Disorders Clinic and the Edmond J. Safra Program in Parkinson's Disease, Division of Neurology, Toronto Western Hospital, UHN, University of Toronto; '2Department of Clinical Epidemiology and Biostatistics, McMaster University, Hamilton, Canada; and '3epartment of Neurology, Academic Medical Center, Amsterdam, The Netherlands

OBJECTIVE Deep brain stimulation (DBS) is effective in the management of patients with advanced Parkinson's disease (PD). While both the globus pallidus pars interna (GPi) and the subthalamic nucleus (STN) are accepted targets, their relative efficacy in randomized controlled trials (RCTs) has not been established beyond 12 months. The objective of this study was to conduct a meta-analysis of RCTs to compare outcomes among adults with PD undergoing DBS of GPi or STN at various time points, including 36 months of follow-up.

METHODS The MEDLINE, Embase, CENTRAL, Web of Science, and CINAHL databases were searched. Registries for clinical trials, selected conference proceedings, and the table of contents for selected journals were also searched. Screens were conducted independently and in duplicate. Among the 623 studies initially identified (615 through database search, 7 through manual review of bibliographies, and 1 through a repeat screen of literature prior to submission), 19 underwent full-text review; 13 of these were included in the quantitative meta-analysis. Data were extracted independently and in duplicate. The Cochrane Collaboration tool was used to assess the risk of bias. The GRADE evidence profile tool was used to assess the quality of the evidence. Motor scores, medication dosage reduction, activities of daily living, depression, dyskinesias, and adverse events were compared. The influence of disease duration (a priori) and the proportion of male patients within a study (post hoc) were explored as potential subgroups.

RESULTS Thirteen studies (6 original cohorts) were identified. No difference in motor scores or activities of daily living was identified at 36 months. Medications were significantly reduced with STN stimulation (5 studies, weighted mean difference [WMD] $-365.46,95 \% \mathrm{Cl}-599.48$ to $-131.44, \mathrm{p}=0.002$ ). Beck Depression Inventory scores were significantly better with GPi stimulation (3 studies; WMD 2.53, 95\% Cl 0.99-4.06 p =0.001). The motor benefits of GPi and STN DBS for PD are similar.

CONCLUSIONS The motor benefits achieved with GPi and STN DBS for PD are similar. DBS of STN allows for a greater reduction of medication, but not as significant an advantage as DBS of GPi with respect to mood. This difference is sustained at 36 months. Further long-term studies are necessary.

https://thejns.org/doi/abs/10.3171/2016.11.JNS16715

KEY WORDS deep brain stimulation; globus pallidus pars interna; meta-analysis; Parkinson's disease; subthalamic nucleus; functional neurosurgery

ABBREVIATIONS AE = adverse event; BDI = Beck Depression Inventory; CDRS = Clinical Dyskinesia Rating Scale; DBS = deep brain stimulation; GPi = globus pallidus pars interna; GRADE = Grading of Recommendations Assessment, Development and Evaluation; IQR = interquartile range; LED = levodopa-equivalent dose; PD = Parkinson's disease; RCT = randomized controlled trial; RR = risk ratio; SE = standard error; STN = subthalamic nucleus; UPDRS = United Parkinson's Disease Rating Scale; WMD = weighted mean difference.

SUBMITTED March 20, 2016. ACCEPTED November 21, 2016.

INCLUDE WHEN CITING Published online June 30, 2017; DOI: 10.3171/2016.11.JNS16715. 
I $\mathrm{N}$ patients with advanced Parkinson's disease (PD), deep brain stimulation (DBS) has been established as a treatment strategy for medically refractory disease. ${ }^{8,34,51,55}$ Accepted targets of DBS for PD include the globus pallidus pars interna (GPi) and the subthalamic nucleus (STN). While STN stimulation may improve motor symptoms, ${ }^{3}$ there are concerns regarding the worsening of axial symptoms and adverse behavioral/neuropsychiatric outcomes. ${ }^{4,22,46,48}$ Stimulation of GPi can lead to motor outcomes equivalent to STN stimulation, although there are concerns that this benefit may not be as sustained. $2,11,13,18,52$ Thus, given the conflicting evidence and the lack of a comprehensive review comparing the 2 targets over a long term follow-up, a systematic review and meta-analysis is warranted.

Three systematic reviews on this topic have been conducted previously. ${ }^{21,40,50}$ Based on primarily observational studies, Weaver and colleagues ${ }^{50}$ concluded that STN was superior to GPi for medication reduction. Focusing on randomized-controlled trials (RCTs) only, Sako et al. ${ }^{40}$ found a benefit in favor of GPi stimulation for depression. Liu et al. ${ }^{21}$ found GPi to be superior regarding depression, while STN was superior for medication reduction. For these last 2 reviews, the inclusion of additional pertinent RCTs would have strengthened the evidence. . $^{5} 29,33,36,38,45,52,57$

Despite the contribution of these studies, there are currently no published reviews that have assessed RCTs with pooled outcomes beyond 12 months of follow-up. In addition, interpretation of results based on a formal evaluation of the quality of evidence (using the GRADE [Grading of Recommendations Assessment, Development and Evaluation] approach) has not been conducted. ${ }^{14}$ Therefore, our objective was to conduct a comprehensive systematic review of RCTs comparing the 2 targets. We have sought to analyze a broader set of outcomes and adverse events (AEs), based on the inclusion of additional studies, along with addressing the aforementioned methodological factors. Outcomes have been assessed overall and separately, according to duration of follow-up.

\section{Methods}

\section{Search Strategy}

The MEDLINE (PubMed/Ovid), Embase, CENTRAL, and Web of Science electronic databases were searched on January 14, 2015. MeSH terms/keywords related to DBS and PD were used. This was supplemented by a search of the bibliographies of included studies and manually screening the tables of contents (2005-2014) of Movement Disorders, Neurology, Archives of Neurology, Annals of Neurology, Stereotactic and Functional Neurosurgery, Journal of Neurosurgery, and Neurosurgery. ClinicalTrials.gov and BioMed Central were also searched to identify upcoming trials. Another search of MEDLINE and Embase was conducted on April 14, 2015, to identify additional publications.

\section{Search Terms}

Our strategy was developed separately for each database, based on terms pertaining to primary PD, DBS, and RCTs as study methodology.

\section{Study Selection}

Title/Abstract Screening and Full-Text Review

All identified references and retrieved full-text articles were reviewed for eligibility, independently and in duplicate (A.M. and S.T.). Kappa scores were calculated to measure agreement. Studies were included if they were based on adults (age $\geq 18$ years) with idiopathic PD and DBS was used as an intervention, with outcomes for each target reported. Neither date nor language was a limitation.

\section{Data Collection}

Data from selected studies were abstracted independently (by A.M. and S.T.), and the accuracy was verified by a third author (J.H.B.). Study characteristics were collected independently and in duplicate (by C.D.W. and F.N.).

\section{Outcomes}

The primary outcomes were ranked by the panel of senior authors. United Parkinson's Disease Rating Scale (UPDRS) III score and change in levodopa-equivalent dose (LED) were deemed "critical" and UPDRS II score was of "high" importance, while neuropsychological impact and procedure-related AEs were judged to be of "moderate" importance. The major AEs sought included dysphagia, dysarthria/speech problems, and axial symptoms (e.g., gait, balance, and postural disturbances). Axial symptoms are established debilitating symptoms associated with PD, and the response of each patient to DBS is not uniform. ${ }^{10}$ For AEs of varying reported severity, the component with the largest number of events was considered.

\section{Quality Assessment of Individual Studies}

Two investigators (A.M. and S.T.) independently performed quality assessment, using the Cochrane Collaboration's tool. ${ }^{16}$ Studies with unexplained deviations from prior protocols/methods and lacking an adequate description of conflicts of interest/sources of funding were judged to have a high risk of "other bias." We judged trials with $\geq 2$ and $\geq 4$ high-risk components as moderate risk and high risk, respectively. Sensitivity analyses were conducted to determine the impact of studies with moderate/high risk of bias.

\section{Overall Quality Assessment of Evidence Grade}

The GRADE guidelines were applied to eligible studies by 2 independent authors (A.M. and S.T.), using GRADEPro software (version 3.6.1; The Cochrane Collaboration).

\section{Statistical Analysis}

Weighted mean differences (WMDs) or risk ratios (RR) with associated $95 \%$ confidence intervals were calculated for continuous and dichotomous outcomes, respectively. Final mean values were preferred. In cases where only a percentage change in mean value was reported, the final value was calculated by subtracting the relative change from the baseline mean values. Pooled summary statistics were calculated using a fixed/random effects (inverse variance) model, depending on the heterogeneity. In cases of values reported as medians (and interquartile ranges [IQRs]), assumptions regarding the normality of distribution were made to obtain the SD through dividing the IQR 


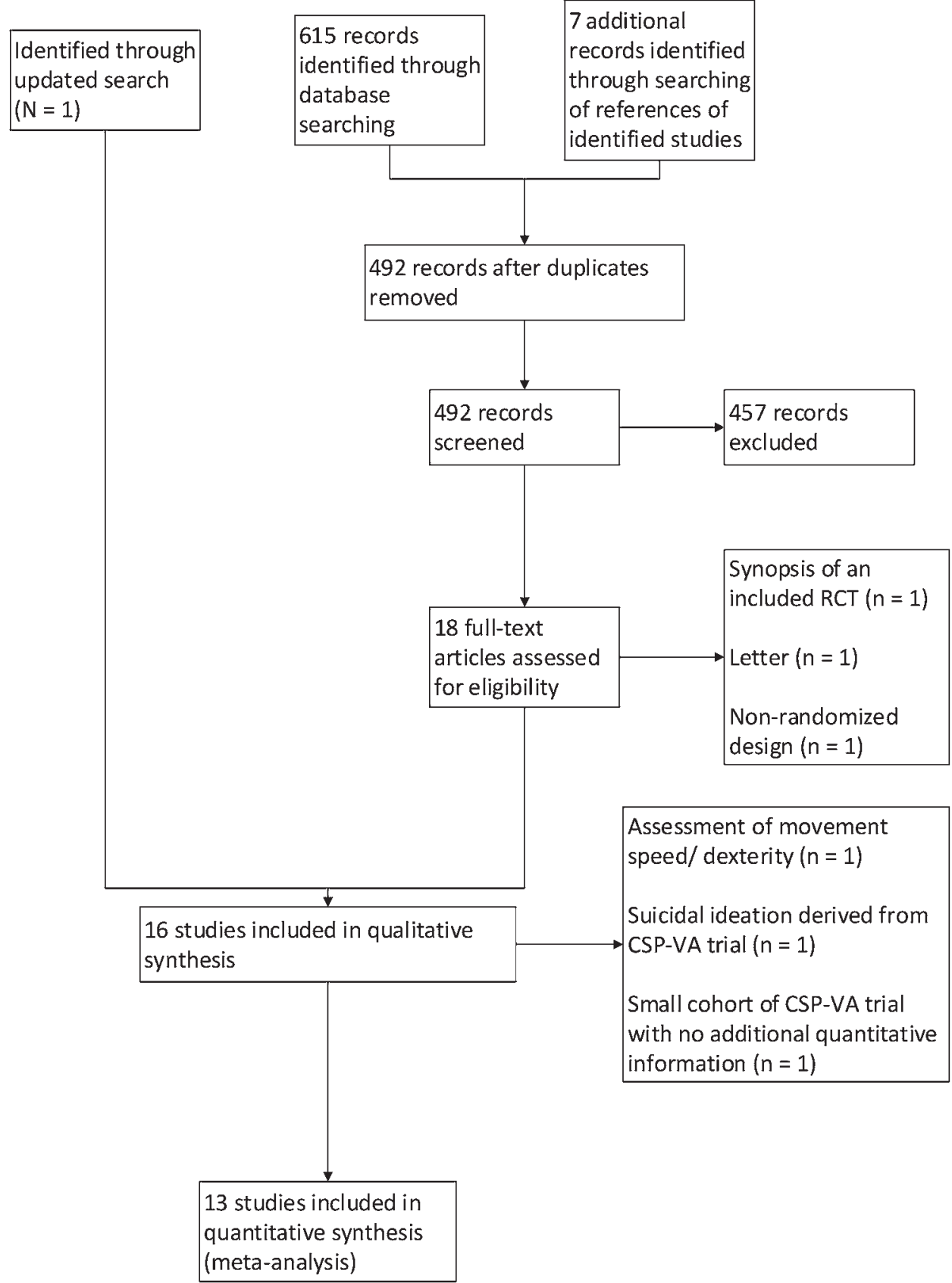

FIG. 1. PRISMA flow diagram, summarizing search strategy and results based on screening of titles/abstracts and full-text articles. An update to the initial search was conducted on April 14, 2015, resulting in the identification of an additional study.

by 1.35 .16 A sensitivity analysis was conducted to assess the robustness of estimates based on this assumption. Between-study heterogeneity was measured by the $\mathrm{I}^{2}$ statistic, with values exceeding $75 \%$ representing high heterogeneity. ${ }^{17}$ Duration of PD and proportion of enrolled males were assessed through subgroup analyses, as described below. Review Manager (v5.3; The Cochrane Collaboration) was used for all other statistical analyses.

\section{Duration of PD (a priori)}

Disease duration can have an impact on response to DBS. ${ }^{42,54}$ The threshold for categorizing studies as short or long PD duration in our analysis was arbitrary and based on a comparison of baseline parameters across studies; studies with an average PD duration $>12$ years were categorized as "long duration."

\section{Proportion of Enrolled Males (post hoc)}

The differential impact of the proportion of enrolled male patients was assessed by comparing outcomes from trials with $>80 \%$ males to those with $<80 \%$ males. This was an arbitrarily selected threshold, but it was based on the range of proportion of males in included studies $(66 \%-87 \%)$. 


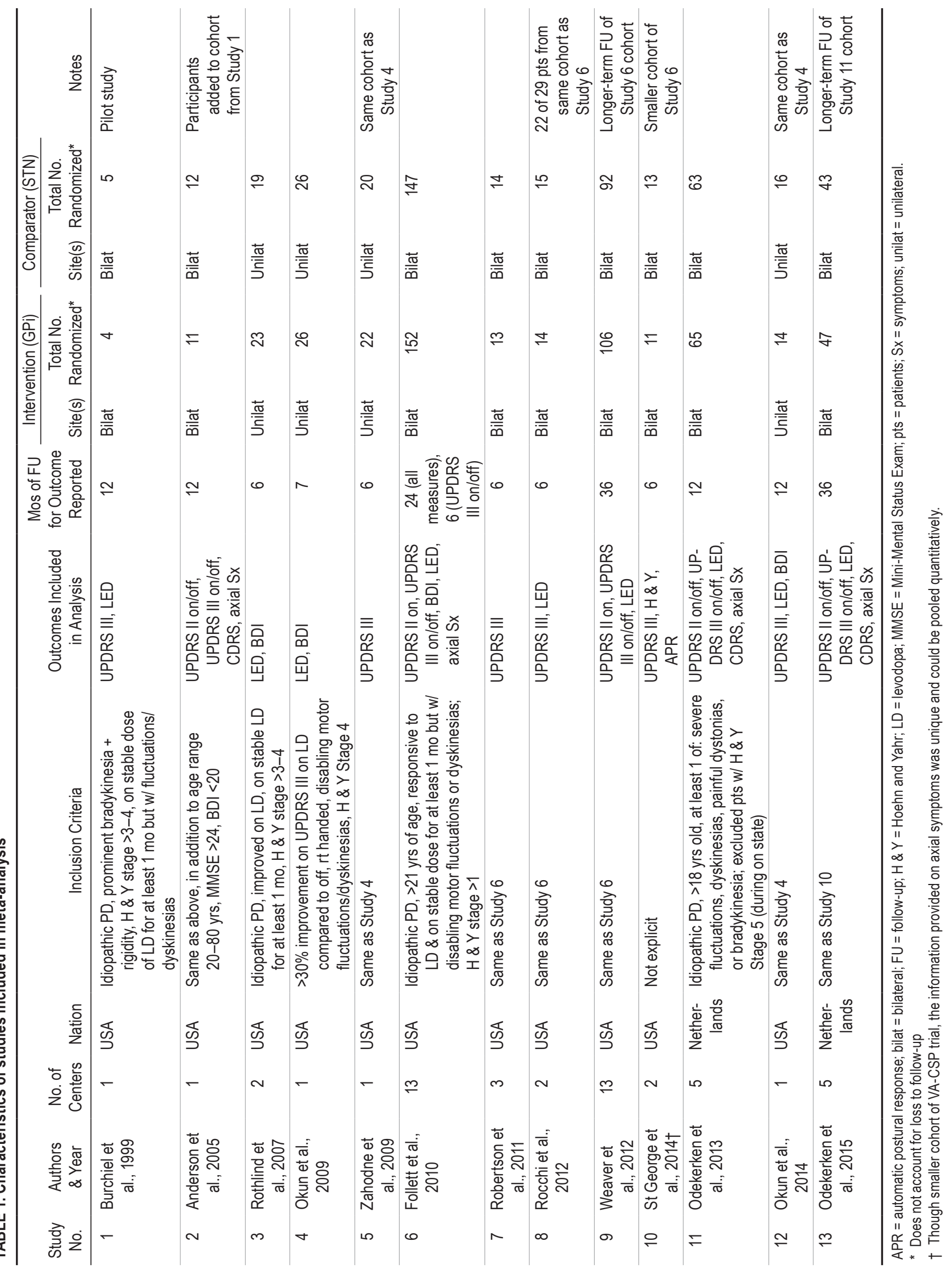


TABLE 2. Characteristics of studies not included in quantitative meta-analysis

\begin{tabular}{|c|c|c|c|c|}
\hline $\begin{array}{l}\text { Authors } \\
\& \text { Year }\end{array}$ & Journal & Article Title & $\begin{array}{l}\text { Reason for Exclusion } \\
\text { from Meta-Analysis }\end{array}$ & Main Conclusions \\
\hline $\begin{array}{l}\text { Nakamura } \\
\text { et al., } \\
2007\end{array}$ & Mov Disord & $\begin{array}{l}\text { "Effects of unilateral subthalamic } \\
\text { and pallidal deep brain stimula- } \\
\text { tion on fine motor functions in } \\
\text { Parkinson's disease" }\end{array}$ & $\begin{array}{l}\text { Reported outcomes were motor } \\
\text { subscales pertinent to dexter- } \\
\text { ity, reaction time, \& move- } \\
\text { ment time; these could not be } \\
\text { pooled w/ remainder of data. }\end{array}$ & $\begin{array}{l}\text { Movement speed \& dexterity were improved through } \\
\text { stimulation of both targets; there was no signifi- } \\
\text { cant difference btwn the } 2 \text { targets }\end{array}$ \\
\hline $\begin{array}{l}\text { Weintraub } \\
\text { et al., } \\
2013\end{array}$ & $\begin{array}{l}\text { J Neurol } \\
\text { Neurosurg } \\
\text { Psyschia- } \\
\text { try }\end{array}$ & $\begin{array}{l}\text { "Suicide ideation and behaviours } \\
\text { after STN and GPi DBS sur- } \\
\text { gery for Parkinson's disease: } \\
\text { results from a randomised, } \\
\text { controlled trial" }\end{array}$ & $\begin{array}{l}\text { Suicidal ideation \& behavior was } \\
\text { derived from pt responses to } \\
\text { UPDRS I; this was in contrast } \\
\text { to the other studies, which } \\
\text { had directly prompted the pts } \\
\text { for this variable. }\end{array}$ & $\begin{array}{l}\text { Pts undergoing GPi stimulation were significantly } \\
\text { happier, more energetic, \& less angry/bitter than } \\
\text { pts undergoing STN stimulation. This was based } \\
\text { on psychological items from the PDQ-39 \& SF-36 } \\
\text { scales. Overall, there was no increased risk of } \\
\text { suicidal ideation or behavior. }\end{array}$ \\
\hline
\end{tabular}

J Neurol Neurosurg Psychiatry = Journal of Neurology, Neurosurgery, and Psychiatry; J Neurosurg = Journal of Neurosurgery; Mov Disord = Movement Disorders; WAIS $=$ Wechsler Adult Intelligence Scale.

\section{Results}

\section{General Study Characteristics}

Thirteen studies (6 original trial cohorts) were identified (Fig. 1, PRISMA [Preferred Reporting Items for Systematic Reviews and Meta-Analyses] flow diagram ${ }^{26}$ ). Their general characteristics are listed in Tables 1-3. Studies excluded from the quantitative meta-analysis have also been listed in Table 2, along with reasons for exclusion..$^{27,28,44,53}$ An almost perfect agreement was noted for both the title/abstract screening (kappa 0.81, standard error [SE] 0.07 ; 95\% CI 0.68-0.95) and the full-text review (kappa 0.89, SE 0.08; 95\% CI 0.73-1).

The majority of trials were multicenter (8 publications, $2-13$ centers), had an average patient age $>60$ years, and had a large proportion of male participants (range $66 \%-87 \%$ ). The duration of follow-up ranged from 6 to 36 months. Three trials were registered a priori. ${ }^{11,30,32}$ Three had a moderate risk of bias, ${ }^{36-38}$ while the remainder had a low risk of bias (Supplementary Fig. 1).

\section{Pooled Outcomes}

The pooled outcomes are shown in Tables 4 and 5. The GRADE Evidence Profile is shown in Supplementary Table 1.

\section{Motor Symptoms On Medication}

The GRADE quality of evidence for this outcome was moderate. Five trials reported UPDRS III scores (on medication); GPi stimulation resulted in a nonstatistically significant improvement ${ }^{1,29,33,36,52}$ (Fig. 2). Pooling reports with similar durations of follow-up did not yield significant differences.

\section{Motor Symptoms Off Medication}

The GRADE quality of evidence for this outcome was very low. Four original trials reported UPDRS III scores (off medication); $1,29,33,52$ STN stimulation resulted in a nonsignificant improvement (Fig. 3). A sensitivity analysis excluding the CSP-VA trial (Weaver et al. ${ }^{52}$ ), due to noticeable variation of mean differences, led to a significant pooled estimate in favor of STN (Table 4): WMD -4.58 (95\% CI -8.71 to -0.44$), p=0.03$. Pooling of studies with similar duration of follow-up suggested an initial benefit in favor of GPi at 6 months but at 12 months a benefit was seen in favor of STN. Subsequently, however, no significant differences were noted. Studies enrolling $<80 \%$ male patients resulted in a significant benefit in favor of STN; this analysis excluded 1 study, which also had the highest proportion of patients lost to follow-up..$^{52}$

\section{Medication Reduction}

The GRADE quality of evidence for this outcome was high. Five original trials reported on LED reduction $^{5,29,33,36,52}$; STN stimulation resulted in a significant benefit (Fig. 4): WMD -365.46 (95\% CI -599.48 to $-131.44), \mathrm{p}=0.002, \mathrm{I}^{2}=58 \%$. Based on the 2 studies with $>80 \%$ males, ${ }^{36,52}$ the stimulation of STN did not result in a significant benefit.

\section{Activities of Daily Living On Medication}

The GRADE quality of evidence for activities of daily living outcome was moderate. Three original trials reported UPDRS II scores (on medication); ;,29,52 GPi stimulation resulted in a nonsignificant benefit (Fig. 5). 


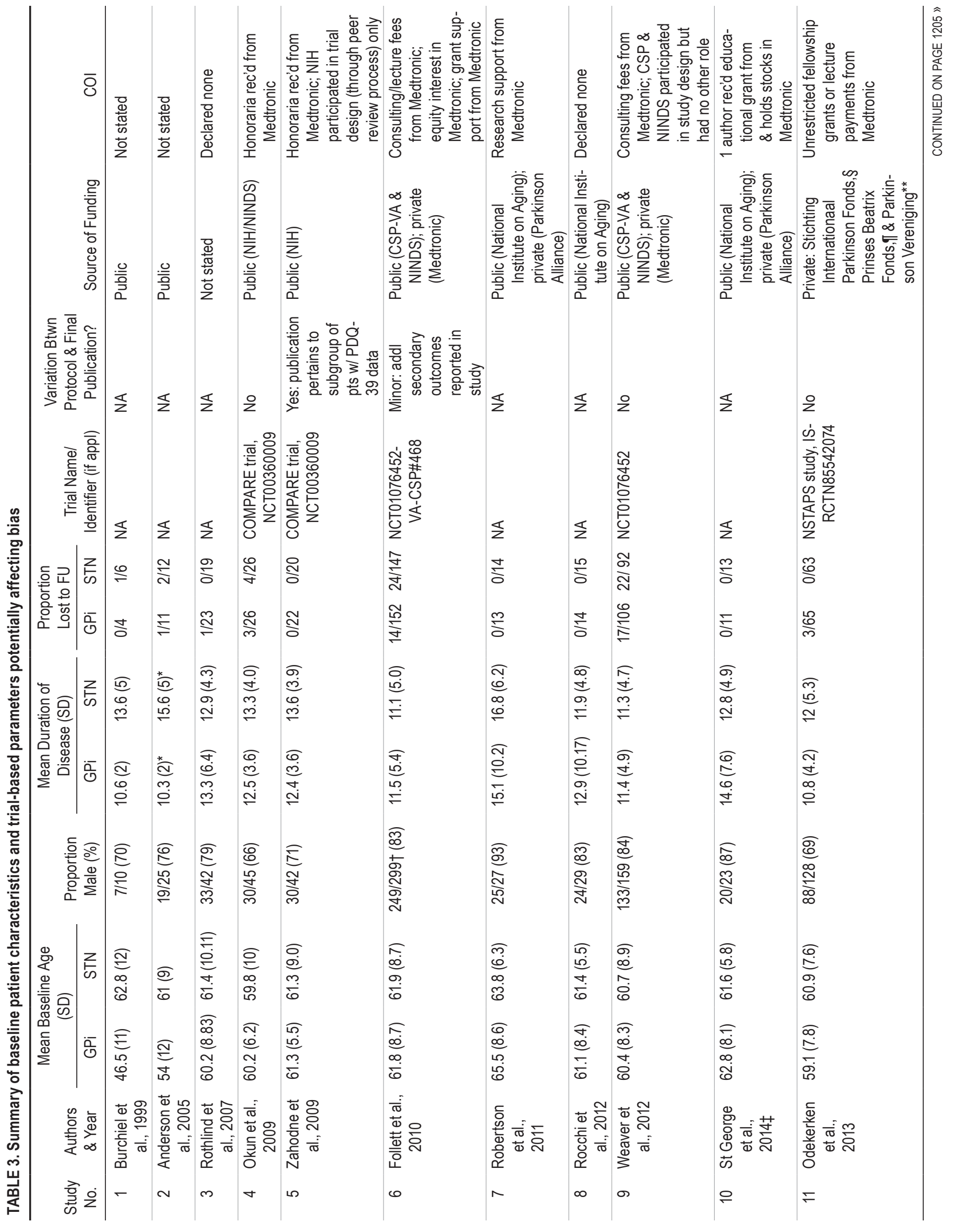




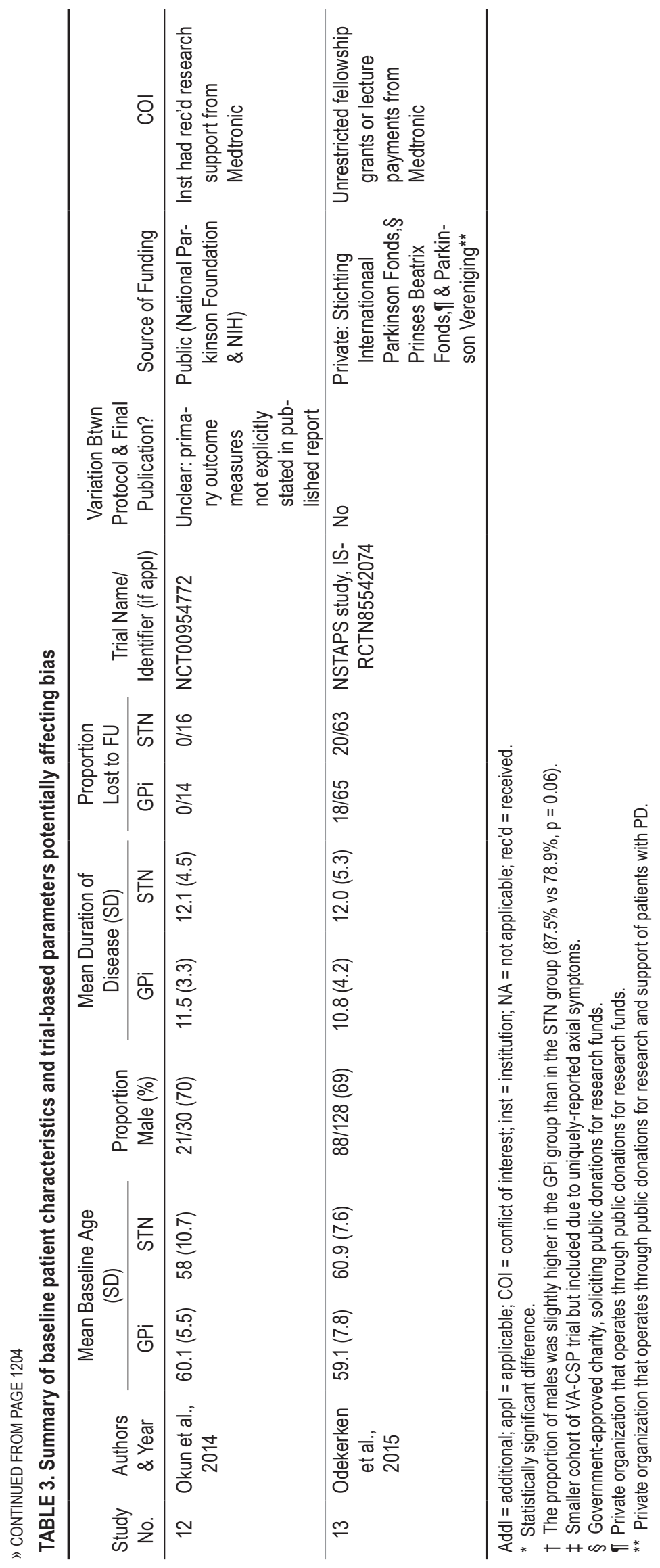


TABLE 4. Summary of pooled statistics for outcomes along with relevant subgroup and sensitivity analyses: continuous variables

\begin{tabular}{|c|c|c|c|c|c|c|c|}
\hline $\begin{array}{c}\text { Outcome \& Relevant } \\
\text { Subgroup/Sensitivity Analyses }\end{array}$ & K & $\begin{array}{c}\text { No. } \\
\text { of } \\
\text { Pts }\end{array}$ & $\begin{array}{l}\text { WMD } \\
{[95 \% \mathrm{Cl}]}\end{array}$ & $\begin{array}{c}p \text { Value } \\
\text { for } \\
\text { WMD }\end{array}$ & Heterogeneity & SMD $[95 \% \mathrm{Cl}]$ & $\begin{array}{l}p \text { Value } \\
\text { for } \\
\text { SMD }\end{array}$ \\
\hline \multicolumn{8}{|l|}{ UPDRS III on medication } \\
\hline All & 5 & 310 & $1.05[-0.43$ to 2.53$]$ & 0.16 & $\chi^{2}=3.19, p=0.53,\left.\right|^{2}=0 \%$ & $0.20[-0.03$ to 0.42$]$ & 0.09 \\
\hline $6 \mathrm{mos}$ & 3 & 368 & $0.59[-0.89$ to 2.07$]$ & 0.44 & $\chi^{2}=0.24, p=0.89,\left.\right|^{2}=0 \%$ & $0.09[-0.12$ to 0.29$]$ & 0.40 \\
\hline $12 \mathrm{mos}$ & 3 & 175 & $-0.33[-3.01$ to 2.35$]$ & 0.81 & $\chi^{2}=1.63, p=0.44,\left.\right|^{2}=0 \%$ & $-0.07[-0.36$ to 0.23$]$ & 0.66 \\
\hline $24 \mathrm{mos}$ & 1 & 299 & $1.80[-0.90$ to 4.50$]$ & 0.19 & - & $0.15[-0.08$ to 0.38$]$ & 0.19 \\
\hline $36 \mathrm{mos}$ & 2 & 233 & $2.38[-0.96$ to 5.72$]$ & 0.16 & $\chi^{2}=1.22, p=0.27,\left.\right|^{2}=18 \%$ & $0.19[-0.14$ to 0.53$]$ & 0.25 \\
\hline \multicolumn{8}{|l|}{ Duration of PD } \\
\hline Longer & 2 & 47 & $0.63[-1.18$ to 2.44$]$ & 0.50 & $\chi^{2}=0.64, p=0.43,\left.\right|^{2}=0 \%$ & $0.26[-0.31$ to 0.84$]$ & 0.37 \\
\hline Shorter & 3 & 263 & $1.89[-0.67$ to 4.46$]$ & 0.15 & $\chi^{2}=1.94, p=0.38,\left.\right|^{2}=0 \%$ & $0.18[-0.06$ to 0.43$]$ & 0.14 \\
\hline \multicolumn{8}{|l|}{ Proportion of males } \\
\hline$<80 \%$ & 3 & 140 & $0.79[-2.41$ to 3.98$]$ & 0.63 & $\chi^{2}=0.70, p=0.71,\left.\right|^{2}=0 \%$ & $0.05[-0.28$ to 0.39$]$ & 0.75 \\
\hline$>80 \%$ & 2 & 170 & $1.12[-0.55$ to 2.79$]$ & 0.19 & $\chi^{2}=2.46, p=0.12,\left.\right|^{2}=59 \%$ & $0.31[0.01$ to 0.62$]$ & 0.04 \\
\hline \multicolumn{8}{|l|}{ Electrode location } \\
\hline Unilat & 1 & 30 & $-0.10[-5.39$ to 5.19$]$ & 0.97 & - & $-0.01[-0.73$ to 0.70$]$ & 0.97 \\
\hline Bilat & 4 & 280 & $1.15[-0.39$ to 2.69$]$ & 0.14 & $\chi^{2}=2.99, p=0.39,1^{2}=0 \%$ & $0.22[-0.02$ to 0.45$]$ & 0.07 \\
\hline $\begin{array}{l}\text { All (actual mean value obtained } \\
\text { from authors) }\end{array}$ & 5 & 310 & $0.92[-0.55$ to 2.38$]$ & 0.22 & $\chi^{2}=3.82, p=0.43,1^{2}=0 \%$ & $0.17[-0.06$ to 0.39$]$ & 0.15 \\
\hline Low risk of bias studies only & 4 & 283 & $2.06[-0.31$ to 4.42$]$ & 0.09 & $\chi^{2}=2.04, p=0.56,\left.\right|^{2}=0 \%$ & $0.20[-0.04$ to 0.43$]$ & 0.10 \\
\hline \multicolumn{8}{|l|}{ UPDRS III off medication } \\
\hline All & 4 & 290 & $-1.76[-6.38$ to 2.85$]$ & 0.45 & $\chi^{2}=6.01, p=0.11,1^{2}=50 \%$ & $-0.07[-0.30$ to 0.17$]$ & 0.58 \\
\hline $6 \mathrm{mos}$ & 3 & 368 & $3.43[1.36-5.50]$ & 0.001 & $\chi^{2}=0.91, p=0.64, I^{2}=0 \%$ & $0.36[-0.12$ to 0.83$]$ & 0.14 \\
\hline $12 \mathrm{mos}$ & 2 & 145 & $-1.97[-4.37$ to 0.43$]$ & 0.11 & $\chi^{2}=0.36, p=0.55,\left.\right|^{2}=0 \%$ & $-0.27[-0.59$ to 0.06$]$ & 0.11 \\
\hline $24 \mathrm{mos}$ & 1 & 299 & $2.10[-1.28$ to 5.48$]$ & 0.22 & - & $0.14[-0.09$ to 0.37$]$ & 0.22 \\
\hline $36 \mathrm{mos}$ & 2 & 240 & $-1.10[-8.45$ to 6.42$]$ & 0.79 & $\chi^{2}=5.11, p=0.02,\left.\right|^{2}=80 \%$ & $-0.08[-0.66$ to 0.51$]$ & 0.80 \\
\hline $\begin{array}{l}\text { All except Study } 9 \text { (Weaver et } \\
\text { al. excluded) }\end{array}$ & 3 & 140 & $-4.58[-8.71$ to -0.44$]$ & 0.03 & $\chi^{2}=0.09, p=0.95,\left.\right|^{2}=0 \%$ & $-0.36[-0.69$ to -0.02$]$ & 0.04 \\
\hline \multicolumn{8}{|l|}{ Duration of PD } \\
\hline Longer & 1 & 20 & $-3.00[-15.55$ to 9.55$]$ & 0.64 & - & $-0.20[-1.08$ to 0.68$]$ & 0.65 \\
\hline Shorter & 3 & 270 & $-0.78[-3.75$ to 2.19$]$ & 0.61 & $\chi^{2}=5.89, p=0.05,\left.\right|^{2}=66 \%$ & $-0.06[-0.30$ to 0.19$]$ & 0.65 \\
\hline \multicolumn{8}{|l|}{ Proportion of males } \\
\hline$<80 \%$ & 3 & 140 & $-4.58[-8.71$ to -0.44$]$ & 0.03 & $\chi^{2}=0.09, p=0.95,\left.\right|^{2}=0 \%$ & $-0.36[-0.69$ to -0.02$]$ & 0.04 \\
\hline$>80 \%$ & 1 & 150 & $2.60[-1.44$ to 6.64$]$ & 0.21 & - & $0.21[-0.12$ to 0.53$]$ & 0.21 \\
\hline \multicolumn{8}{|l|}{ Electrode location } \\
\hline Unilat & 1 & 30 & $-4.20[-12.33$ to 3.93$]$ & 0.31 & - & $-0.36[-1.09$ to 0.36$]$ & 0.32 \\
\hline Bilat & 3 & 260 & $-1.27[-7.11$ to 4.57$]$ & 0.67 & $\chi^{2}=5.28, p=0.07,\left.\right|^{2}=62 \%$ & $-0.09[-0.54$ to 0.35$]$ & 0.68 \\
\hline $\begin{array}{l}\text { Actual mean value obtained } \\
\text { from authors }\end{array}$ & 4 & 290 & $-1.97[-6.86$ to 2.91$]$ & 0.43 & $\chi^{2}=6.47, p=0.09,\left.\right|^{2}=54 \%$ & $-0.15[-0.53$ to 0.23$]$ & 0.45 \\
\hline \multicolumn{8}{|l|}{ LED reduction } \\
\hline All & 5 & 314 & $-365.46[-599.48$ to -131.44$]$ & 0.002 & $\chi^{2}=9.51, P=0.05, I^{2}=58 \%$ & $-0.61[-0.98$ to -0.24$]$ & 0.001 \\
\hline $6 \mathrm{mos}$ & 3 & 116 & $-283.20[-476.56$ to -89.83$]$ & 0.004 & $\chi^{2}=1.10, P=0.58, I^{2}=0 \%$ & $-0.53[-0.90$ to -0.16$]$ & 0.005 \\
\hline 12 mos & 3 & 164 & $-470.17[-634.36$ to -305.98$]$ & $<0.001$ & $\chi^{2}=2.19, p=0.33,\left.\right|^{2}=9 \%$ & $-0.88[-1.20$ to -0.56$]$ & $<0.001$ \\
\hline $24 \mathrm{mos}$ & 1 & 299 & $-231.00[-356.48$ to -105.52$]$ & $<0.001$ & - & $-0.42[-0.65$ to -0.19$]$ & $<0.001$ \\
\hline $36 \mathrm{mos}$ & 2 & 249 & $-334.82[-467.86$ to -201.79$]$ & $<0.001$ & $\chi^{2}=0.96, p=0.33,\left.\right|^{2}=0 \%$ & $-0.63[-0.88$ to -0.37$]$ & $<0.001$ \\
\hline \multicolumn{8}{|l|}{ Proportion of males } \\
\hline$<80 \%$ & 3 & 129 & $-542.09[-762.91$ to -321.28$]$ & $<0.001$ & $\chi^{2}=1.43, p=0.49,\left.\right|^{2}=0 \%$ & $-0.80[-1.17$ to -0.44$]$ & $<0.001$ \\
\hline$>80 \%$ & 2 & 186 & $-131.56[-544.39$ to 281.28$]$ & 0.53 & $\chi^{2}=3.38, p=0.07,\left.\right|^{2}=70 \%$ & $-0.27[-1.07$ to 0.54$]$ & 0.52 \\
\hline
\end{tabular}


» CONTINUED FROM PAGE 1206

TABLE 4. Summary of pooled statistics for outcomes along with relevant subgroup and sensitivity analyses: continuous variables

\begin{tabular}{|c|c|c|c|c|c|c|c|}
\hline $\begin{array}{c}\text { Outcome \& Relevant } \\
\text { Subgroup/Sensitivity Analyses }\end{array}$ & $K$ & $\begin{array}{c}\text { No. } \\
\text { of } \\
\text { Pts }\end{array}$ & $\begin{array}{c}\text { WMD } \\
{[95 \% \mathrm{Cl}]}\end{array}$ & $\begin{array}{l}p \text { Value } \\
\text { for } \\
\text { WMD }\end{array}$ & Heterogeneity & SMD $[95 \% \mathrm{Cl}]$ & $\begin{array}{l}p \text { Value } \\
\text { for } \\
\text { SMD }\end{array}$ \\
\hline \multicolumn{8}{|l|}{ LED reduction (continued) } \\
\hline \multicolumn{8}{|l|}{ Electrode location } \\
\hline Unilat & 1 & 30 & $-778.00[-1230.50$ to -325.50$]$ & $<0.001$ & - & $-1.24[-2.04$ to -0.45$]$ & 0.002 \\
\hline Bilat & 5 & 313 & $-274.63[-446.84$ to -102.41$]$ & 0.002 & $\chi^{2}=6.11, p=0.19,\left.\right|^{2}=35 \%$ & $-0.50[-0.79$ to -0.22$]$ & $<0.001$ \\
\hline $\begin{array}{l}\text { Actual mean value obtained } \\
\text { from authors }\end{array}$ & 6 & 343 & $-356.02[-569.73$ to -142.30$]$ & 0.001 & $\chi^{2}=12.78, p=0.03,\left.\right|^{2}=61 \%$ & $-0.63[-0.99$ to -0.28$]$ & $<0.001$ \\
\hline Low risk of bias studies only & 5 & 316 & $-382.43[-550.19$ to -214.67$]$ & $<0.001$ & $\chi^{2}=5.82, p=0.21,\left.\right|^{2}=31 \%$ & $-0.66[-0.89$ to -0.43$]$ & $<0.001$ \\
\hline \multicolumn{8}{|l|}{ UPDRS II on medication } \\
\hline All & 3 & 267 & $1.18[-0.35$ to 2.70$]$ & 0.13 & $\chi^{2}=0.73, p=0.70,1^{2}=0 \%$ & $0.18[-0.07$ to 0.42$]$ & 0.16 \\
\hline $6 \mathrm{mos}$ & 1 & 42 & $-0.10[-5.65$ to 5.45$]$ & 0.97 & - & $-0.01[-0.62$ to 0.59$]$ & 0.97 \\
\hline $12 \mathrm{mos}$ & 2 & 145 & $0.94[-0.93$ to 2.80$]$ & 0.33 & $\chi^{2}=0.99, p=0.32,\left.\right|^{2}=0 \%$ & $0.15[-0.18$ to 0.47$]$ & 0.37 \\
\hline $24 \mathrm{mos}$ & 1 & 299 & $1.00[-0.48$ to 2.48$]$ & 0.18 & - & $0.15[-0.07$ to 0.38$]$ & 0.19 \\
\hline $36 \mathrm{mos}$ & 2 & 247 & $0.94[-0.68$ to 2.55$]$ & 0.26 & $\chi^{2}=0.00, p=0.95,\left.\right|^{2}=0 \%$ & $0.15[-0.11$ to 0.40$]$ & 0.26 \\
\hline \multicolumn{8}{|l|}{ Duration of PD } \\
\hline Longer & 1 & 20 & $3.00[-1.47$ to 7.47$]$ & 0.19 & - & $0.56[-0.33$ to 1.46$]$ & 0.22 \\
\hline Shorter & 2 & 247 & $0.94[-0.68$ to 2.56$]$ & 0.26 & $\chi^{2}=0.00, p=0.95,\left.\right|^{2}=0 \%$ & $0.14[-0.11$ to 0.40$]$ & 0.26 \\
\hline \multicolumn{8}{|l|}{ Proportion of males } \\
\hline$<80 \%$ & 2 & 110 & $1.53[-0.77$ to 3.84$]$ & 0.19 & $\chi^{2}=0.56, p=0.45,\left.\right|^{2}=0 \%$ & $0.22[-0.15$ to 0.60$]$ & 0.24 \\
\hline$>80 \%$ & 1 & 157 & $0.90[-1.13$ to 2.93$]$ & 0.38 & - & $0.14[-0.18$ to 0.46$]$ & 0.38 \\
\hline $\begin{array}{l}\text { Actual mean value obtained } \\
\text { from authors }\end{array}$ & 3 & 267 & $1.24[-0.28$ to 2.75$]$ & 0.11 & $\chi^{2}=0.70, p=0.70,\left.\right|^{2}=0 \%$ & $0.19[-0.06$ to 0.43$]$ & 0.13 \\
\hline UPDRS II off medication, all & 2 & 110 & $-1.44[-4.11$ to 1.24$]$ & 0.29 & $\chi^{2}=0.60, p=0.44,\left.\right|^{2}=0 \%$ & $-0.20[-0.58$ to 0.17$]$ & 0.29 \\
\hline Depression (based on BDI), all & 3 & 371 & $2.53[0.99-4.06]$ & 0.001 & $\chi^{2}=0.17, p=0.92,\left.\right|^{2}=0 \%$ & $0.34[0.13-0.54]$ & 0.001 \\
\hline Dyskinesias (based on CDRS), all & 2 & 110 & $1.32[-0.06$ to 2.70$]$ & 0.06 & $\chi^{2}=0.97, p=0.32,\left.\right|^{2}=0 \%$ & $0.37[-0.00$ to 0.75$]$ & 0.05 \\
\hline $\begin{array}{l}\text { Posture \& gait (sum of Items } \\
27-30 \text { on UPDRS III) }\end{array}$ & 2 & 149 & $0.45[-0.49$ to 1.39$]$ & 0.35 & $\chi^{2}=0.06, p=0.81,\left.\right|^{2}=0 \%$ & $0.15[-0.17$ to 0.47$]$ & 0.35 \\
\hline
\end{tabular}

SMD = standardized mean difference.

\section{Quality of Life}

Three studies reported on quality of life. ${ }^{11,30,57}$ In the NSTAPS trial, the PDQL (Parkinson's Disease Quality of Life) scale was used, and no significant difference was noted. The COMPARE and VA-CSP trials used the PDQ-39 scale, and while the former showed significant improvements through GPi (38\%) versus STN (14\%), the latter showed no overall difference. Given the variation in scales used and the individualized reporting of scale items, overall quality of life data were not pooled.

\section{Depression}

Three original trials reported Beck Depression Inventory (BDI) scores, ${ }^{11,33,38}$ suggesting an advantage in favor of GPi: WMD 2.53 (95\% CI 0.99-4.06), $\mathrm{p}=0.001, \mathrm{I}^{2}=$ $0 \%$. A significant difference was noted in patients undergoing GPi stimulation with respect to continuous but not categorical variables (Tables 4 and 5, respectively).

\section{Adverse Events}

Two trials reported on dyskinesias (Clinical Dyskine-

TABLE 5. Summary of pooled statistics for outcomes: categorical variables

\begin{tabular}{|c|c|c|c|c|c|c|c|c|}
\hline Outcome & K & $\begin{array}{l}\text { No. } \\
\text { of Pts } \\
\text { (GPi) }\end{array}$ & $\begin{array}{c}\text { No. of } \\
\text { Events } \\
\text { (GPi) }\end{array}$ & $\begin{array}{l}\text { No. } \\
\text { of Pts } \\
\text { (STN) }\end{array}$ & $\begin{array}{l}\text { No. of } \\
\text { Events } \\
\text { (STN) }\end{array}$ & $\operatorname{RR}[95 \% \mathrm{Cl}]$ & $\begin{array}{l}\text { p Value } \\
\text { (overall) }\end{array}$ & Heterogeneity \\
\hline Depression (pt reported), all & 3 & 240 & 45 & 232 & 61 & $1.42[0.87-2.33]$ & 0.16 & $\chi^{2}=2.23, p=0.33,\left.\right|^{2}=10 \%$ \\
\hline Dysphagia (pt reported), all & 2 & 57 & 1 & 53 & 3 & $2.46[0.38-16.07]$ & 0.35 & $\chi^{2}=0.03, p=0.87,1^{2}=0 \%$ \\
\hline Dysarthria/speech issues (pt reported), all & 3 & 230 & 64 & 232 & 76 & $1.19[0.91-1.57]$ & 0.21 & $\chi^{2}=1.66, p=0.44,1^{2}=0 \%$ \\
\hline
\end{tabular}




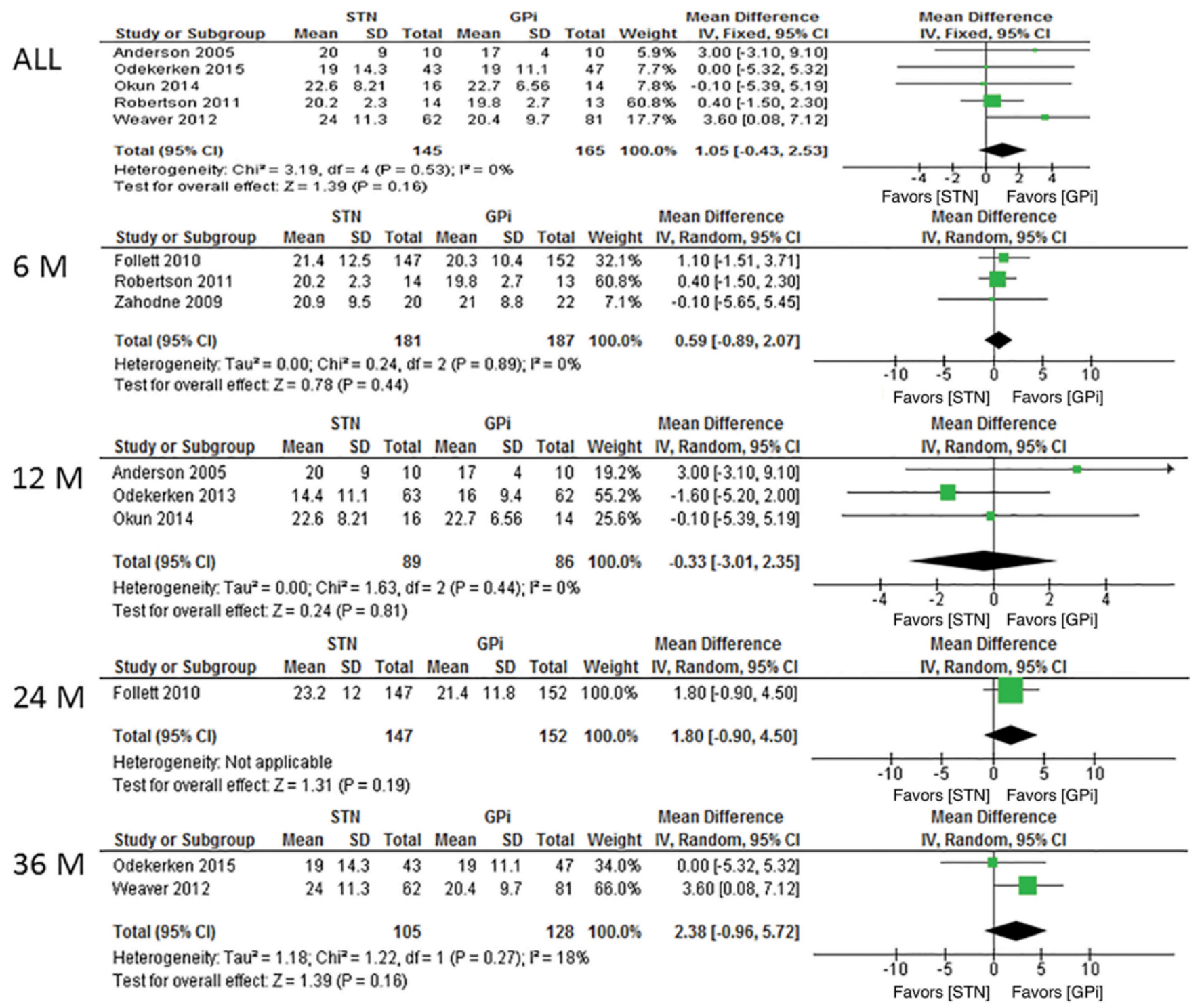

FIG. 2. Pooled overall UPDRS III on-medication scores. Figure is available in color online only.

sia Rating Scale [CDRS], on medication), ${ }^{1,29}$ suggesting a trend in favor of GPi. Off-medication CDRS scores were only reported in 1 study; ${ }^{29}$ no significant difference was noted (Table 4).

Two studies reported on dysphagia, ${ }^{1,29}$ and 3 reported on dysarthria/speech difficulties. ${ }^{11,30,32}$ Pooling these results suggested a nonsignificant benefit in favor of GPi stimulation. Six studies reported outcomes pertinent to the assessment of axial symptoms. ${ }^{1,11,29,30,44,45}$ Only 2 studies were pooled quantitatively, due to similarities in UPDRS III subitems measured, and no significant overall differences were noted (Table 4). In the 24-month report of VA-CSP, ${ }^{11}$ only severe falls were significantly higher in the STN cohort $(8.8 \%$ vs $3.3 \%, p=0.05)$. Assessing the sum of Items 29 and 30 of the UPDRS III scale, St George et al..$^{45}$ showed a postoperative benefit in favor of GPi $(p=0.048)$. Using the activities-specific balance confidence scale, the authors reported improvements in the postoperative outcomes in the GPi cohort $(\mathrm{p}=0.05)$ only, compared with baseline.

\section{Discussion}

This meta-analysis is the first of its kind to include pooled outcome comparisons of RCTs based on PD patients undergoing STN vs GPI DBS for follow-up periods beyond 12 months. The 2 targets were comparable in terms of improvement of UPDRS II and III scores, whether on or off medication. Stimulation of STN led to a significant reduction of medication dosage, while GPi stimulation resulted in significantly better BDI scores. These findings were qualitatively similar to the 2 other systematic reviews of RCTs, ${ }^{21,40}$ suggesting that differences in outcomes through stimulation of either target carry forward to 36 months of follow-up. There was no significant difference in disabling dyskinesias, dysphagia, or dysarthria/speech across targets. The evidence regarding axial symptoms was contradictory. The only outcome with a high quality of evidence was medication dosage reduction. 


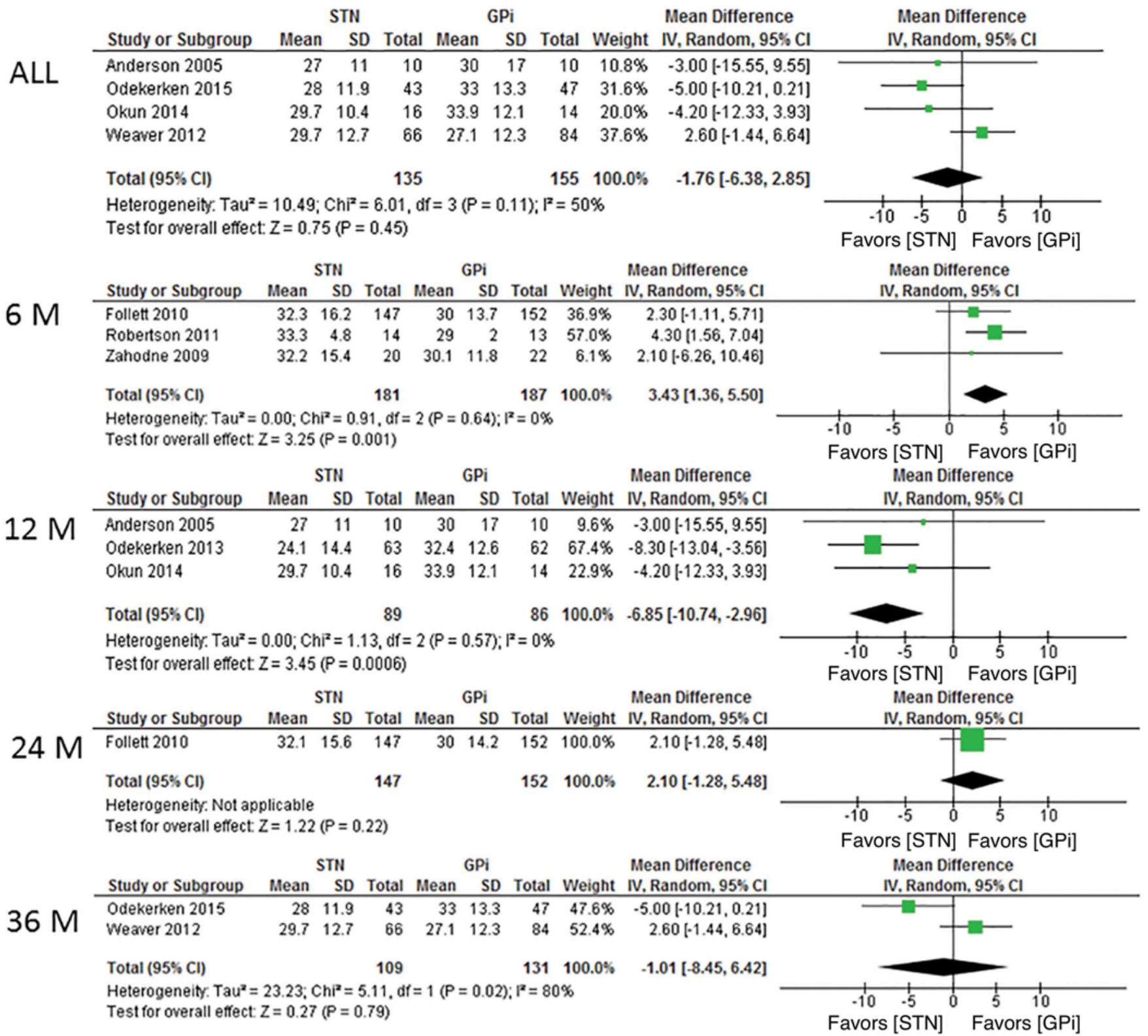

FIG. 3. Pooled overall UPDRS III off-medication scores. Figure is available in color online only.

\section{Motor Outcomes}

Although the pooled summary of both studies with 36-month outcomes (on and off phases) showed no difference, the off-phase summary statistic was associated with a high degree of heterogeneity. ${ }^{29,52}$ This is likely attributable to the variable methodological approaches, with one study conducting stimulation setting and medication dosage adjustments in a blinded manner. This possibility is further strengthened by demonstration of a significant benefit in favor of the STN, through an exclusion of the CSP-VA trial, in our sensitivity analysis. In addition, the variation of pooled results between 6-month, 12-month, and 36-month data may be illustrative of regression toward the mean, further confirming the need for long-term follow-up.

In a post hoc subgroup analysis of studies in which less than $80 \%$ of patients were male, an improvement in off phase symptoms was noted in STN patients. Males have been shown to be susceptible to more severe PD, ${ }^{15}$ while females undergoing STN stimulation are thought to be more susceptible to "brittle dyskinesias", ${ }^{33}$ therefore, exploration of the interaction of sex and target could be informative.

\section{Medication Dosage Reductions}

Stimulation of the STN enabled a greater reduction of medication. Studies of patients with a longer duration of $\mathrm{PD}^{36,45}$ or groups with a higher proportion of males ${ }^{36,45,52}$ did not observe this benefit. Long-term medication therapy has been speculated to induce changes at the gene and cellular level, ${ }^{6,7}$ while the progressive degeneration of dopamine production is thought to lower the threshold for dyskinesias. ${ }^{35}$ Therefore, in patients with advanced PD, it 


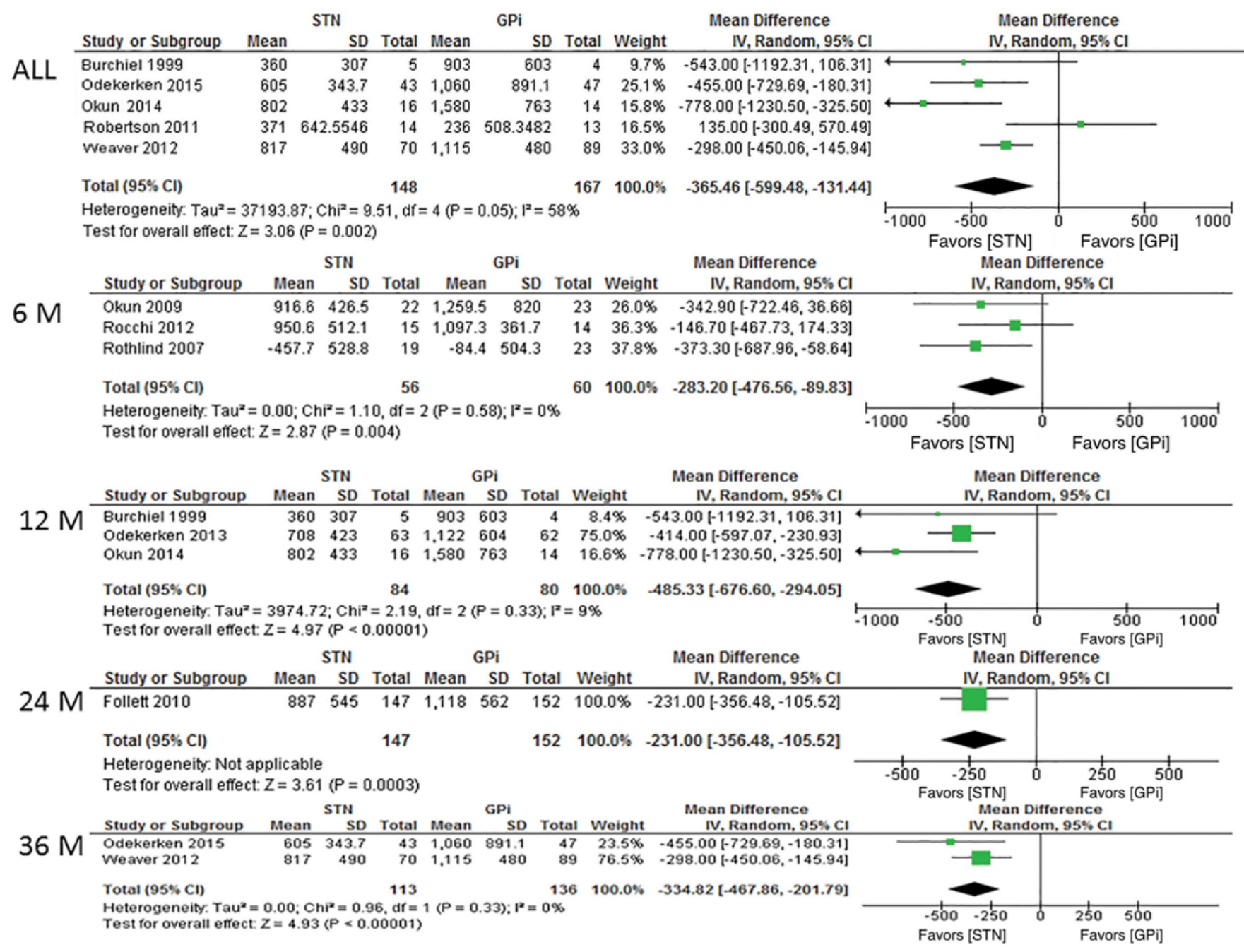

FIG. 4. Pooled overall levodopa-equivalent dosages. Figure is available in color online only.

is possible that stimulation of either target may not compensate for the extensive neurodegeneration. Future RCTs examining the differential impact of these 2 parameters would be enlightening.

\section{Depression}

The advantage of GPi stimulation in terms of depression is qualitatively consistent with the findings of other studies. ${ }^{11,21,39}$ The vicinity of the STN to structures with extensive connectivity with the limbic system ${ }^{24}$ implies that slight variations in electrode placement within the STN could adversely affect mood symptoms. The rapid withdrawal of medication afforded by STN stimulation can also be a factor. Alternatively, it must be borne in mind that these conclusions are mainly driven by the single largest trial with data available on this outcome and additional studies would help strengthen conclusions.

\section{Adverse Events}

GPi stimulation resulted in a trend toward dyskinesia reduction in the on-medication phase. Therefore, patients with levodopa-induced dyskinesias in whom a reduction of medication cannot be attained (e.g., due to dopaminergic, drug-responsive mood symptoms) could benefit from GPi stimulation instead. ${ }^{39}$

The progression of dysarthria and dysphagia can be influenced by DBS. This is particularly true with stimulation of the STN, due to its vicinity to corticobulbar pathways. ${ }^{20,39,47}$ In our review, the reported rates of either outcome were similar across both targets. More robust methods of event documentation, supplemented with a comparison with presurgical patient status, are necessary.

The evidence regarding the correlation of axial symptoms and target site was conflicting. The between-study heterogeneity can be attributed to variations in study methodology, differences in choice of summative evaluation of the subcomponents of UPDRS III, or use of other scales altogether. Furthermore, although the 12-month data from the NSTAPS trial ${ }^{30}$ favored the STN, this latter difference was not sustained at 36 months. ${ }^{29}$ The within-study difference may be due to disease progression. In addition, gait and balance are a reflection of a complex interaction of PD-related symptoms with cortical, subcortical, and spinal pathways. ${ }^{45}$ Ultimately, stimulation of either target may re- 


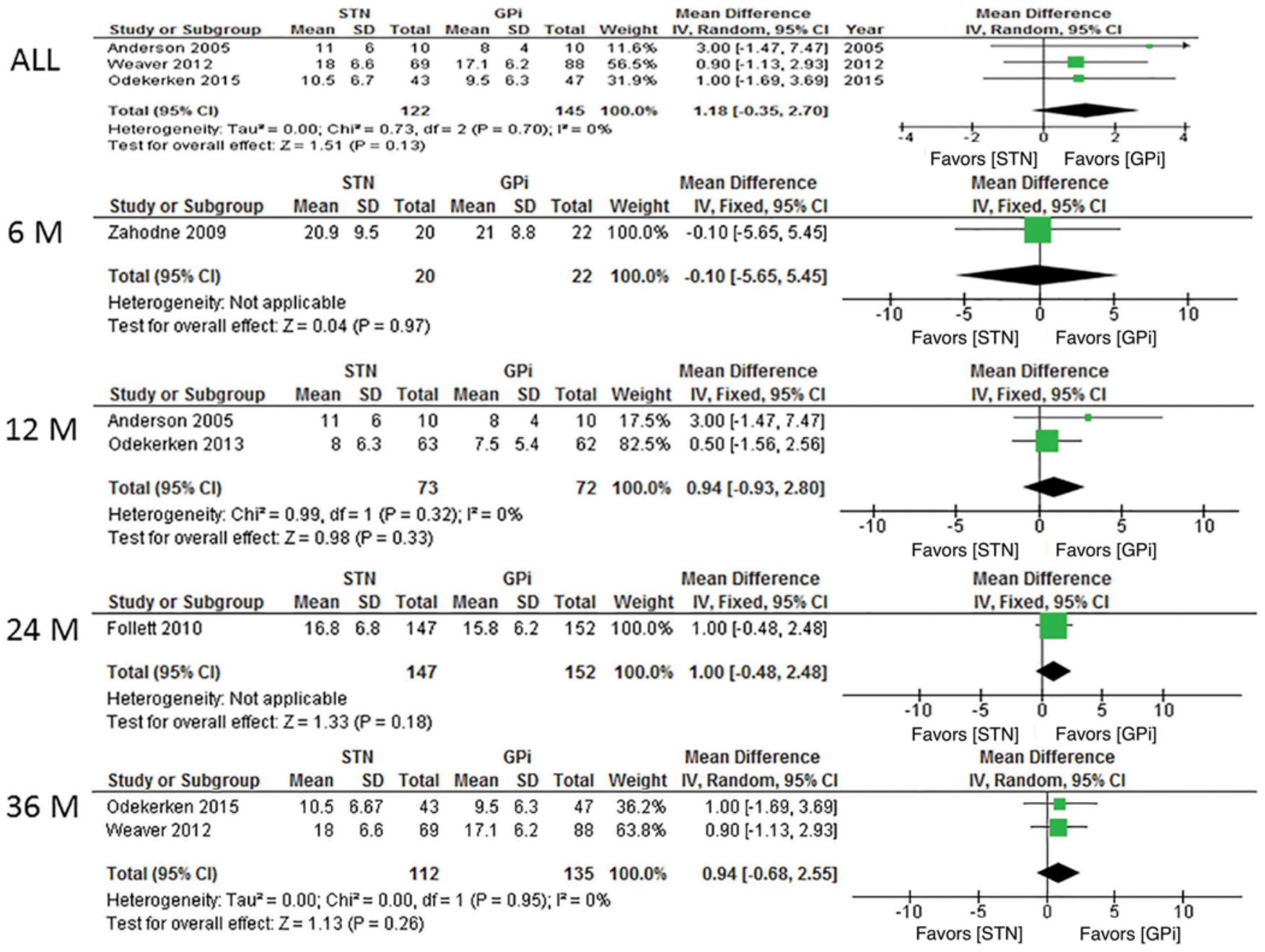

FIG. 5. Pooled overall UPDRS II on-medication scores. Figure is available in color online only.

sult in similar overall outcomes, and specific patient- and stimulation-dependent parameters are contributory.

\section{Implications for Practice}

The current evidence points to the clear superiority of STN stimulation for reduction of medication. However, caution must be advised against aggressive medication reduction in light of the deterioration of nonmotor symptoms and the influence of these symptoms on quality of life. ${ }^{41}$ The concurrent influence of the aging-associated cognitive decline and that observed in PD highlights the importance of conservative dosage reduction. The results of the RCT examining the 6-month neurocognitive outcomes of PD patients with mild cognitive impairment undergoing DBS will be informative (NCT01870518; clinicaltrials.gov).

\section{Implications for Research}

Inadvertent stimulation of undesired segments within the STN and GPi nuclei, or traversing other nuclei such as the caudate, ${ }^{56}$ partly explains the adverse effects associated with DBS in PD patients. Therefore, accurate placement of electrodes is critical, ${ }^{12}$ and the DBS experience and case volume history of physicians involved in the care of patients would presumably be a factor. ${ }^{25,31}$ The lack of a unified method of assessing this parameter prevented us from analyzing its influence; the literature can benefit from uniform reporting of this factor in future trials.

A priori and post hoc subgroup analyses suggested a potential influence of sex and duration of PD on some outcomes. Whether DBS should be offered at an earlier point in the disease process remains controversial, ${ }^{19,23,42}$ and various parameters such as patient age and duration of PD must be considered in patient selection. ${ }^{9,49}$ Future trials can more closely examine the role of these variables.

\section{Limitations}

This review was limited by the small number of studies, the nonuniform reporting of outcomes-particularly for AEs - and our various methodological assumptions. In addition, not all subgroups were based on a priori hypotheses, and arbitrary thresholds were used for comparisons. Nonetheless, this is the first review to report pooled estimate of outcomes at 36 months and to provide a summary of outcomes at varying time points of follow-up, based on a 
more comprehensive set of publications identified through our systematic search. Furthermore, outcomes were ranked by a panel with experience in DBS for PD and the overall quality of evidence was evaluated using the GRADE approach.

\section{Acknowledgments}

We would like to acknowledge Dr. Gordon Guyatt for his input and support, and Ms. Laura Banfield with regard to the bibliographic search strategies for this protocol.

\section{References}

1. Anderson VC, Burchiel KJ, Hogarth P, Favre J, Hammerstad JP: Pallidal vs subthalamic nucleus deep brain stimulation in Parkinson disease. Arch Neurol 62:554-560, 2005

2. Barcia-Salorio JL, Roldan P, Talamantes F, Pascual-Leone A: Electrical inhibition of basal ganglia nuclei in Parkinson's disease: long-term results. Stereotact Funct Neurosurg 72:202-207, 1999

3. Benabid AL, Chabardes S, Mitrofanis J, Pollak P: Deep brain stimulation of the subthalamic nucleus for the treatment of Parkinson's disease. Lancet Neurol 8:67-81, 2009

4. Beric A, Kelly PJ, Rezai A, Sterio D, Mogilner A, Zonenshayn M, et al: Complications of deep brain stimulation surgery. Stereotact Funct Neurosurg 77:73-78, 2001

5. Burchiel KJ, Anderson VC, Favre J, Hammerstad JP: Comparison of pallidal and subthalamic nucleus deep brain stimulation for advanced Parkinson's disease: results of a randomized, blinded pilot study. Neurosurgery 45:1375-1384, 1999

6. Calabresi P, Di Filippo M, Ghiglieri V, Tambasco N, Picconi B: Levodopa-induced dyskinesias in patients with Parkinson's disease: filling the bench-to-bedside gap. Lancet Neurol 9:1106-1117, 2010

7. Caraceni T, Scigliano G, Musicco M: The occurrence of motor fluctuations in parkinsonian patients treated long term with levodopa: role of early treatment and disease progression. Neurology 41:380-384, 1991

8. Deuschl G, Schade-Brittinger C, Krack P, Volkmann J, Schäfer H, Bötzel K, et al: A randomized trial of deep-brain stimulation for Parkinson's disease. N Engl J Med 355:896908, 2006

9. Eggington S, Valldeoriola F, Chaudhuri KR, Ashkan K, Annoni E, Deuschl G: The cost-effectiveness of deep brain stimulation in combination with best medical therapy, versus best medical therapy alone, in advanced Parkinson's disease. J Neurol 261:106-116, 2014

10. Fasano A, Aquino CC, Krauss JK, Honey CR, Bloem BR: Axial disability and deep brain stimulation in patients with Parkinson disease. Nat Rev Neurol 11:98-110, 2015

11. Follett KA, Weaver FM, Stern M, Hur K, Harris CL, Luo P, et al: Pallidal versus subthalamic deep-brain stimulation for Parkinson's disease. N Engl J Med 362:2077-2091, 2010

12. Frankemolle AM, Wu J, Noecker AM, Voelcker-Rehage C, Ho JC, Vitek JL, et al: Reversing cognitive-motor impairments in Parkinson's disease patients using a computational modelling approach to deep brain stimulation programming. Brain 133:746-761, 2010

13. Ghika J, Villemure JG, Fankhauser H, Favre J, Assal G, Ghika-Schmid F: Efficiency and safety of bilateral contemporaneous pallidal stimulation (deep brain stimulation) in levodopa-responsive patients with Parkinson's disease with severe motor fluctuations: a 2-year follow-up review. J Neurosurg 89:713-718, 1998

14. Guyatt GH, Oxman AD, Schünemann HJ, Tugwell P, Knottnerus A: GRADE guidelines: a new series of articles in the Journal of Clinical Epidemiology. J Clin Epidemiol 64:380-382, 2011

15. Haaxma CA, Bloem BR, Borm GF, Oyen WJ, Leenders KL,
Eshuis S, et al: Gender differences in Parkinson's disease. J Neurol Neurosurg Psychiatry 78:819-824, 2007

16. Higgins JP, Altman DG, Gøtzsche PC, Jüni P, Moher D, Oxman AD, et al: The Cochrane Collaboration's tool for assessing risk of bias in randomised trials. BMJ 343:d5928, 2011

17. Higgins JP, Thompson SG, Deeks JJ, Altman DG: Measuring inconsistency in meta-analyses. BMJ 327:557-560, 2003

18. Houeto JL, Bejjani PB, Damier P, Staedler C, Bonnet AM, Pidoux B, et al: Failure of long-term pallidal stimulation corrected by subthalamic stimulation in PD. Neurology 55:728730,2000

19. Kalia SK, Lozano AM: Parkinson disease: Neurostimulation in PD-benefit of early surgery revealed. Nat Rev Neurol 9:244-245, 2013

20. Krack P, Batir A, Van Blercom N, Chabardes S, Fraix V, Ardouin $C$, et al: Five-year follow-up of bilateral stimulation of the subthalamic nucleus in advanced Parkinson's disease. N Engl J Med 349:1925-1934, 2003

21. Liu Y, Li W, Tan C, Liu X, Wang X, Gui Y, et al: Meta-analysis comparing deep brain stimulation of the globus pallidus and subthalamic nucleus to treat advanced Parkinson disease. J Neurosurg 121:709-718, 2014

22. Merola A, Zibetti M, Angrisano S, Rizzi L, Ricchi V, Artusi CA, et al: Parkinson's disease progression at 30 years: a study of subthalamic deep brain-stimulated patients. Brain 134:2074-2084, 2011

23. Mestre TA, Espay AJ, Marras C, Eckman MH, Pollak P, Lang AE: Subthalamic nucleus-deep brain stimulation for early motor complications in Parkinson's disease-the EARLYSTIM trial: early is not always better. Mov Disord 29:1751-1756, 2014

24. Middleton FA, Strick PL: Basal ganglia and cerebellar loops: motor and cognitive circuits. Brain Res Brain Res Rev 31:236-250, 2000

25. Minguez-Castellanos A, Escamilla-Sevilla F, Katati MJ, Martin-Linares JM, Meersmans M, Ortega-Moreno A, et al: Different patterns of medication change after subthalamic or pallidal stimulation for Parkinson's disease: target related effect or selection bias? J Neurol Neurosurg Psychiatry 76:34-39, 2005

26. Moher D, Liberati A, Tetzlaff J, Altman DG: Preferred reporting items for systematic reviews and meta-analyses: the PRISMA statement. J Clin Epidemiol 62:1006-1012, 2009

27. Nakamura K, Christine CW, Starr PA, Marks WJ Jr: Effects of unilateral subthalamic and pallidal deep brain stimulation on fine motor functions in Parkinson's disease. Mov Disord 22:619-626, 2007

28. Odekerken VJ, Boel JA, Geurtsen GJ, Schmand BA, Dekker IP, de Haan RJ, et al: Neuropsychological outcome after deep brain stimulation for Parkinson disease. Neurology 84:13551361,2015

29. Odekerken VJ, Boel JA, Schmand BA, de Haan RJ, Figee M, van den Munckhof P, et al: GPI vs STN deep brain stimulation for Parkinson disease: three-year follow-up. Neurology 86:755-761, 2016

30. Odekerken VJ, van Laar T, Staal MJ, Mosch A, Hoffmann CF, Nijssen PC, et al: Subthalamic nucleus versus globus pallidus bilateral deep brain stimulation for advanced Parkinson's disease (NSTAPS study): a randomised controlled trial. Lancet Neurol 12:37-44, 2013

31. Oh MY, Abosch A, Kim SH, Lang AE, Lozano AM: Longterm hardware-related complications of deep brain stimulation. Neurosurgery 50:1268-1276, 2002

32. Okun MS, Fernandez HH, Wu SS, Kirsch-Darrow L, Bowers D, Bova F, et al: Cognition and mood in Parkinson's disease in subthalamic nucleus versus globus pallidus interna deep brain stimulation: the COMPARE trial. Ann Neurol 65:586595, 2009

33. Okun MS, Wu SS, Fayad S, Ward H, Bowers D, Rosado C, et al: Acute and chronic mood and apathy outcomes from a ran- 
domized study of unilateral STN and GPi DBS. PLoS One 9:e114140, 2014

34. Olanow CW, Stern MB, Sethi K: The scientific and clinical basis for the treatment of Parkinson disease (2009). Neurology 72 (21 Suppl 4):S1-S136, 2009

35. Paillé V, Brachet P, Damier P: Role of nigral lesion in the genesis of dyskinesias in a rat model of Parkinson's disease. Neuroreport 15:561-564, 2004

36. Robertson LT, St George RJ, Carlson-Kuhta P, Hogarth P, Burchiel KJ, Horak FB: Site of deep brain stimulation and jaw velocity in Parkinson disease. J Neurosurg 115:985994, 2011

37. Rocchi L, Carlson-Kuhta P, Chiari L, Burchiel KJ, Hogarth P, Horak FB: Effects of deep brain stimulation in the subthalamic nucleus or globus pallidus internus on step initiation in Parkinson disease: laboratory investigation. J Neurosurg 117:1141-1149, 2012

38. Rothlind JC, Cockshott RW, Starr PA, Marks WJ Jr: Neuropsychological performance following staged bilateral pallidal or subthalamic nucleus deep brain stimulation for Parkinson's disease. J Int Neuropsychol Soc 13:68-79, 2007

39. Rouaud T, Dondaine T, Drapier S, Haegelen C, Lallement F, Péron J, et al: Pallidal stimulation in advanced Parkinson's patients with contraindications for subthalamic stimulation. Mov Disord 25:1839-1846, 2010

40. Sako W, Miyazaki Y, Izumi Y, Kaji R: Which target is best for patients with Parkinson's disease? A meta-analysis of pallidal and subthalamic stimulation. J Neurol Neurosurg Psychiatry 85:982-986, 2014

41. Schrag A, Jahanshahi M, Quinn N: How does Parkinson's disease affect quality of life? A comparison with quality of life in the general population. Mov Disord 15:1112-1118, 2000

42. Schuepbach WM, Rau J, Knudsen K, Volkmann J, Krack P, Timmermann L, et al: Neurostimulation for Parkinson's disease with early motor complications. N Engl J Med 368:610-622, 2013

43. Sriram A, Foote KD, Oyama G, Kwak J, Zeilman PR, Okun MS: Brittle dyskinesia following STN but not GPi deep brain stimulation. Tremor Other Hyperkinet Mov (N Y) 4:242, 2014

44. St George RJ, Carlson-Kuhta P, Burchiel KJ, Hogarth P, Frank N, Horak FB: The effects of subthalamic and pallidal deep brain stimulation on postural responses in patients with Parkinson disease. J Neurosurg 116:1347-1356, 2012

45. St George RJ, Carlson-Kuhta P, Nutt JG, Hogarth P, Burchiel KJ, Horak FB: The effect of deep brain stimulation randomized by site on balance in Parkinson's disease. Mov Disord 29:949-953, 2014

46. Temel Y, Kessels A, Tan S, Topdag A, Boon P, Visser-Vandewalle V: Behavioural changes after bilateral subthalamic stimulation in advanced Parkinson disease: a systematic review. Parkinsonism Relat Disord 12:265-272, 2006

47. Tripoliti E, Zrinzo L, Martinez-Torres I, Frost E, Pinto S, Foltynie T, et al: Effects of subthalamic stimulation on speech of consecutive patients with Parkinson disease. Neurology 76:80-86, 2011

48. Tripoliti E, Zrinzo L, Martinez-Torres I, Tisch S, Frost E, Borrell E, et al: Effects of contact location and voltage amplitude on speech and movement in bilateral subthalamic nucleus deep brain stimulation. Mov Disord 23:2377-2383, 2008

49. Valldeoriola F, Morsi O, Tolosa E, Rumià J, Martí MJ, Martínez-Martín P: Prospective comparative study on costeffectiveness of subthalamic stimulation and best medical treatment in advanced Parkinson's disease. Mov Disord 22:2183-2191, 2007

50. Weaver F, Follett K, Hur K, Ippolito D, Stern M: Deep brain stimulation in Parkinson disease: a metaanalysis of patient outcomes. J Neurosurg 103:956-967, 2005

51. Weaver FM, Follett K, Stern M, Hur K, Harris C, Marks WJ $\mathrm{Jr}$, et al: Bilateral deep brain stimulation vs best medical ther- apy for patients with advanced Parkinson disease: a randomized controlled trial. JAMA 301:63-73, 2009

52. Weaver FM, Follett KA, Stern M, Luo P, Harris CL, Hur $\mathrm{K}$, et al: Randomized trial of deep brain stimulation for Parkinson disease: thirty-six-month outcomes. Neurology 79:55-65, 2012

53. Weintraub D, Duda JE, Carlson K, Luo P, Sagher O, Stern $\mathrm{M}$, et al: Suicide ideation and behaviours after STN and GPi DBS surgery for Parkinson's disease: results from a randomised, controlled trial. J Neurol Neurosurg Psychiatry 84:1113-1118, 2013

54. Welter ML, Houeto JL, Tezenas du Montcel S, Mesnage V, Bonnet AM, Pillon B, et al: Clinical predictive factors of subthalamic stimulation in Parkinson's disease. Brain 125:575-583, 2002

55. Williams A, Gill S, Varma T, Jenkinson C, Quinn N, Mitchell R, et al: Deep brain stimulation plus best medical therapy versus best medical therapy alone for advanced Parkinson's disease (PD SURG trial): a randomised, open-label trial. Lancet Neurol 9:581-591, 2010

56. Witt K, Granert O, Daniels C, Volkmann J, Falk D, van Eimeren T, et al: Relation of lead trajectory and electrode position to neuropsychological outcomes of subthalamic neurostimulation in Parkinson's disease: results from a randomized trial. Brain 136:2109-2119, 2013

57. Zahodne LB, Okun MS, Foote KD, Fernandez HH, Rodriguez RL, Wu SS, et al: Greater improvement in quality of life following unilateral deep brain stimulation surgery in the globus pallidus as compared to the subthalamic nucleus. J Neurol 256:1321-1329, 2009

\section{Disclosures}

Dr. Odekerken reports receiving payments and travel grants from Medtronic. Dr. de Bie reports receiving grants from Medtronic, GE Health, ZonMw, Parkinson Vereniging, Stitching Parkinson Funds, and the Kinetics Foundation. Dr. Kalia reports receiving payment for lectures from Medtronic. Dr. Fasano reports a consultant relationship with Medtronic and Boston Scientific; receiving grants from the Michael J. Fox foundation and the McLaughlin Center; receiving payment for lectures from Abbvie, Boston Scientific, UCB Pharma, Novartis, TEVA Canada, Chiesi Farmaceutici; and receiving payments for educational presentations from Medtronic. Dr. Lozano reports receiving consultant payments from Medtronic, St. Jude, and Boston Scientific, and being the Co-Founder of Functional Neuromodulation Inc.

\section{Author Contributions}

Conception and design: Mansouri, Lozano. Acquisition of data: Mansouri, Taslimi, Badhiwala, Witiw, Nassiri. Analysis and interpretation of data: Mansouri, Taslimi, Badhiwala. Drafting the article: Mansouri, Taslimi. Critically revising the article: all authors. Reviewed submitted version of manuscript: all authors. Approved the final version of the manuscript on behalf of all authors: Mansouri. Statistical analysis: Mansouri, Taslimi, Badhiwala. Study supervision: Lozano.

\section{Supplemental Information \\ Online-Only Content}

Supplemental material is available with the online version of the article.

Supplementary Fig. 1 and Supplementary Table 1. https://the jns.org/doi/suppl/10.3171/2016.11.JNS16715.

\section{Correspondence}

Alireza Mansouri, Division of Neurosurgery, Toronto Western Hospital, 399 Bathurst St., 4th Fl., West Wing, Toronto, ON M5T2S8, Canada. email: alireza.mansouri@utoronto.ca. 